\title{
Structure of Rust Layer Formed on Atmospheric Corrosion Resistant Steel ${ }^{*}$
}

\author{
By Taishi MOROISHI, ${ }^{* *}$ Jiro SATAKE, ${ }^{* *}$ Nobukatsu FUJINO, ${ }^{* *}$ and Masamichi KOWAKA**
}

\section{Synopsis}

The distribution of elements in rust layer formed on low alloy steels after several periods of exposures up to seven years in industrial and rural atmospheres was investigated by means of microscopic examination and electron probe microanalysis. The rust layer in large pits contains copper, phosphorus, and chromium with their localized distribution. Chromium and phosphorus concentrate around defects in the rust such as voids and cracks. The local concentration of copper seems to diminish as the exposure period becomes longer. The rust layer on the flat surface surrounding large pits and also the surface layer above large pits have shown no evidence of localized concentration of copper and phosphorus and are characterized by the fact that little chromium content is found in the rust. Silicon, main constituent of dusts, has been found in these parts of the rust, but none in the pits. It is supposed that chromium, phosphorus, and copper transferred by corrosion reaction into the solution presumably form far less soluble compounds than ferrous ion which diffuses out from the pits and precipitates on outer surface.

\section{Introduction}

Atmospheric corrosion resistant steels contain copper, chromium, and, in certain cases, phosphorus as the essential alloying elements for the corrosion resistance. The effect of these elements on atmospheric corrosion resistance is thought to become operative after they are transferred into rust layer. Although it is not affirmative from chemical analysis of the whole rust for these elements to be concentrated as compared with contents in the steel, ${ }^{1,2)}$ their local concentration in the rust layer has been observed by electron probe micro-analysis (EPMA). ${ }^{3,4)}$ It has been reported that these alloying elements impart protectiveness to rust layer as a result of affecting the formation of certain iron oxide in the rust layer. ${ }^{4-6)}$ Since the local concentration of the alloying elements, which has not been fully investigated yet, possibly influences protectiveness of rust layer formed on atmospheric corrosion resistant steel, the distribution of the alloying elements and its variation with time and location of atmospheric exposure tests were studied.

\section{Experimental Procedure}

Chemical composition of the test materials is given in Table 1. Test specimens which were $3 \mathrm{~mm}$ thick, $60 \mathrm{~mm}$ wide and $100 \mathrm{~mm}$ long, were cut from hotrolled steel sheets and were ground to remove mill scale. Atmospheric exposure tests have been made at Amagasaki, Japan, marine industrial area, where the atmosphere is highly polluted and at Nagano, Japan, inland rural city, for various periods up to seven years.

Some of the specimens after exposure tests were chemically derusted to evaluate corrosion loss and weight of adherent rust. The derusted steel surface was also examined by a profile meter. The others were dipped in unpolimerized diallyl resin liquid of low viscosity in a vacuum chamber until the resin penetrated into the rust layer, then heated at $100^{\circ} \mathrm{C}$ for polymerization of the resin. The mounted specimens were carefully dry-polished and then finished by oil dispersed abrasive for microscopic examination.

\section{Results and Discussion}

Change of surface appearance of the specimens exposed at Amagasaki with time is as follows. Though the initial rusting varied depending on weathering conditions, in a certain case, the surface was uniformly covered by powdery brown rust after about ten days. Tiny pits were observed on the steel surface but streaks of grinding were still visible and corrosion loss was insignificant. After a month the pits grew and the streaks had already disappeared. Rather large pits were scattered among the numerous small pits densely distributed. After three months the rust surface showed considerable irregularity. Black granular rust was formed in the brown rust. The steel surface was overspread with small pits besides dotted large pits of approximately $0.2 \mathrm{~mm}$ in diameter. The density of the large pits of the low alloy steel was smaller than that of the carbon steel. Till three months the differences in appearance of the steel surface and corrosion loss between the low alloy steel and the carbon steel were insignificant as shown in Fig. 1. They became, however, greater afterwards.

Table 1. Chemical composition of steels (wt \%)

\begin{tabular}{|c|c|c|c|c|c|c|c|c|c|}
\hline Elements & $\mathrm{C}$ & $\mathrm{Si}$ & $\mathrm{Mn}$ & $\mathrm{P}$ & $\mathrm{S}$ & $\mathrm{Cu}$ & $\mathrm{Ni}$ & $\mathrm{Cr}$ & $\mathrm{Ti}$ \\
\hline Low alloy steel $A$ & 0.08 & 0.65 & 0.76 & 0.069 & 0.019 & 0.41 & 0.21 & 0.40 & 0.06 \\
\hline Low alloy steel $B$ & 0.10 & 0.21 & 0.58 & 0.087 & 0.020 & 0.45 & 0.35 & 0.75 & - \\
\hline Carbon steel & 0.08 & 0.01 & 0.36 & 0.007 & 0.019 & 0.06 & 0.04 & 0.01 & - \\
\hline
\end{tabular}

* Originally published in Tetsu-to-Hagané, 56(1970), 1342, in Japanese. English version received May 15, 1971.

** Central Research Laboratories, Sumitomo Metal Industries, Ltd,, Nishinagasu-hondori, Amagasaki 660. 
After twelve months the large pits on the carbon steel almost joined each other while those on the low alloy steel were surrounded by comparatively even surface where pits remained small. The carbon steel was covered predominantly by reddish brown rust layer and black rust partly developed. On the other hand a half of the surface of the low alloy steel had already turned black. Little change of appearance of the rust with time had been observed since the second year. Black rust covered the whole surface of the low alloy steel where dotted pits were surrounded by comparatively smooth surface. The carbon steel surface was also covered by the black rust but since a number of pits contained reddish brown rust, it looked reddish while surface of the low alloy steel looked black or blackish violet.

Figure 2 shows profiles of the corroded surfaces after derusting. Rapid growth of pits associated with high corrosion rate was observed in the first year. Generally the growth rates of pits decreased afterwards. The pits formed on the low alloy steel specimens seemed to cease the growth after the second year while those on the carbon steel specimens retained a certain growth rate.

Weight of adherent rust increased rapidly in the

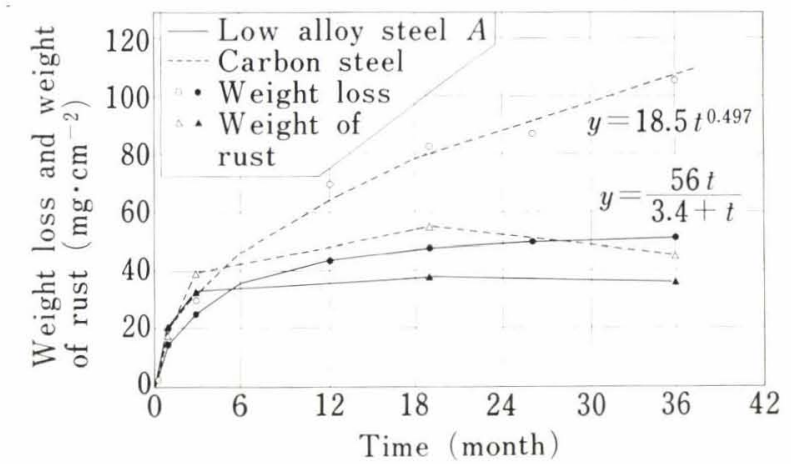

Fig. 1. Weight loss and weight of rust layer of low alloy steel $A$ and carbon steel $v$ s. time of atmospheric exposure

Carbon stecl 1 month $0.1 \mathrm{~mm}-1 \mathrm{~mm}$

Fig. 2. Surface profiles of corroded steels first three months and then little change of the weight was observed as shown in Fig. 1. Comparison of corrosion loss with the iron content of the adherent rust obtained by chemical analysis shows that more than $60 \%$ of the rust initially formed on both steels remained on the specimen surface as the adherent rust during the first three months, but only some ten per cent of the rust formed remained on the surface and the rest ran out from the surface after three months.

Photograph 1 shows microstructures of the cross section of the rust layer formed on the low alloy steel and the carbon steel indicating the difference in development of pits between the steels, the rust layer containing considerable micro-cracks and voids. Cross sections of the rust layer formed on the low alloy steel were examined by EPMA in order to investigate the distribution of the elements. Electron beam scanning images are shown in Photo. 2. The local concentrations of chromium, phosphorus, copper, and sulfur are observed. Chromium, phosphorus, and copper concentrations in the rust within and above the pits are high except the rust at the interface between rust and metal and at the same level as the surface surrounding the pits (approximately $120 \mu$ from the rust-metal interface). The rust in the central portion of pits contains a cluster of voids. High concentration of chromium and phosphorus surrounding these voids is observed. The site of copper concentration not always corresponds to that of chromium.

It would be interesting to investigate the distribution of the alloying elements in the rust on the surface surrounding pits. Microphotograph of the cross section of the rust formed on low alloy steel $A$ exposed at Amagasaki for three years is shown in Photo. 3. The rust within pits also contains cracks and voids shown in Photo. 4 at higher magnification. The
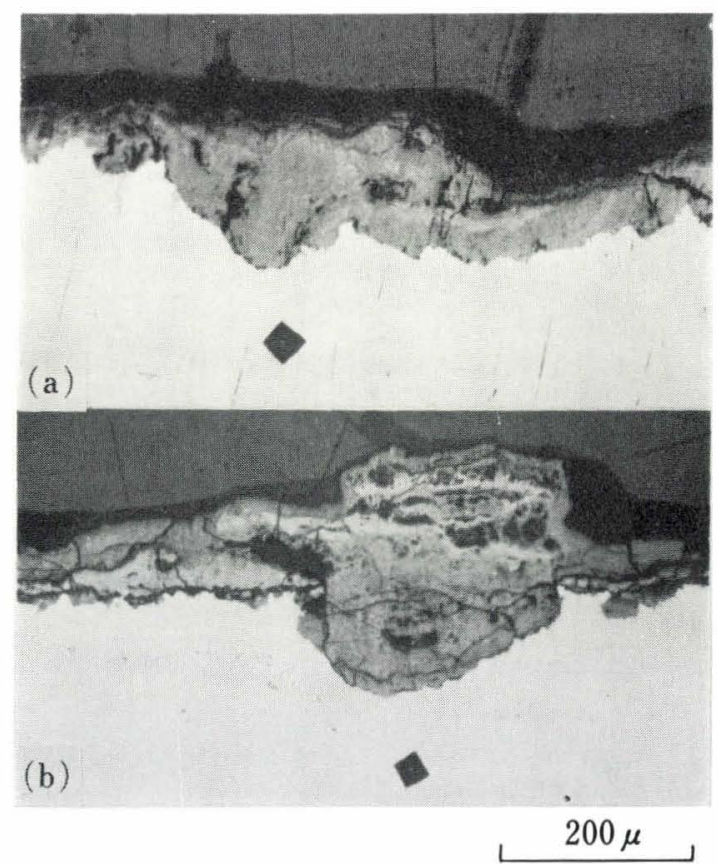

Photo. 1. Microstructure of the rust layers formed by 19 months' atmospheric exposure

(a) Carbon steel (b) Low alloy steel 
distribution of the alloying elements in the rust within pits shown in Photo. 5 is summarized as follows.

Sulfur: the rust contains considerable quantity of sulfur as compared with sulfur content in the steel.

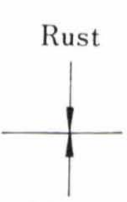

Metal

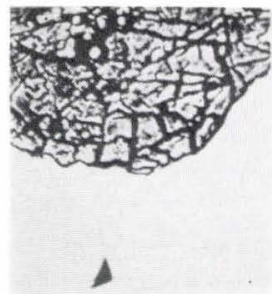

B.S.E.

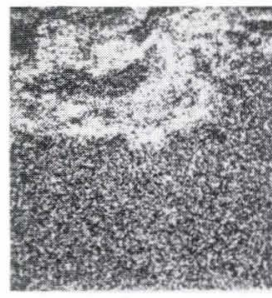

$\mathrm{Cr}$

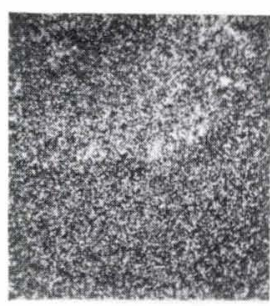

$\mathrm{Cu}$

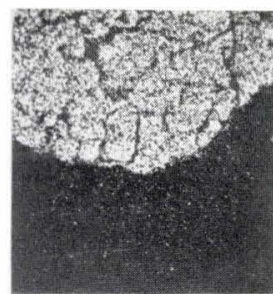

$\mathrm{O}$

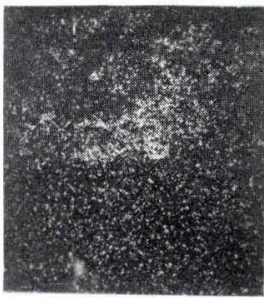

$\mathrm{P}$

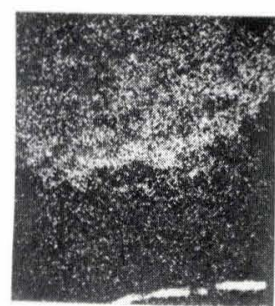

$\mathrm{S}$

$$
100 \mu
$$

Photo. 2. EBS images of EPMA showing localized distribution of $\mathrm{Cr}, \mathrm{P}, \mathrm{Cu}$, and $\mathrm{S}$ in the rust layer of low alloy steel $A$ (BSE: back scattered electron image)
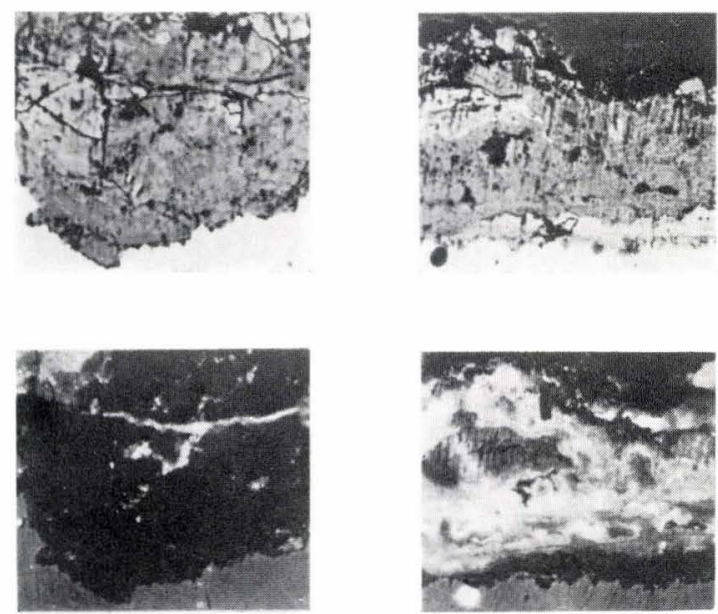

$50 \mu$

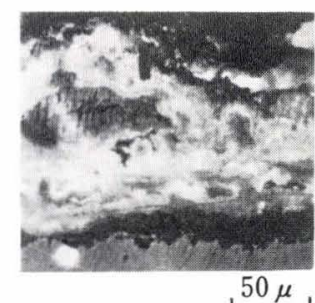

Photo. 3. Microstructures of the rust layers formed on low alloy steel $A$ by three years' atmospheric exposure in industrial area, upper left: rust in a large pit, upper right: rust on a part of less pitted surface surrounding large pits, lower two: reflected polarized light images of the same area as upper two
Concentrated portions are dotted in the rust.

Copper: copper is distributed over the whole rust and concentration phenomenon became uncommon in comparison with the rust formed in the early stages of atmospheric exposure. Merely a few spots of high concentration which coincide with the sulfur concentration can be seen.

Chromium: distinct concentration of chromium around voids is observed.

Phosphorus: phosphorus is slightly concentrated around voids like chromium.

Nickel: no local concentration of nickel is observed.

Manganese: no local concentration of manganese is observed.

Silicon: the rust within pits does not contain silicon, while the rust on pits does.

The rust layer on the relatively smooth surface sur-

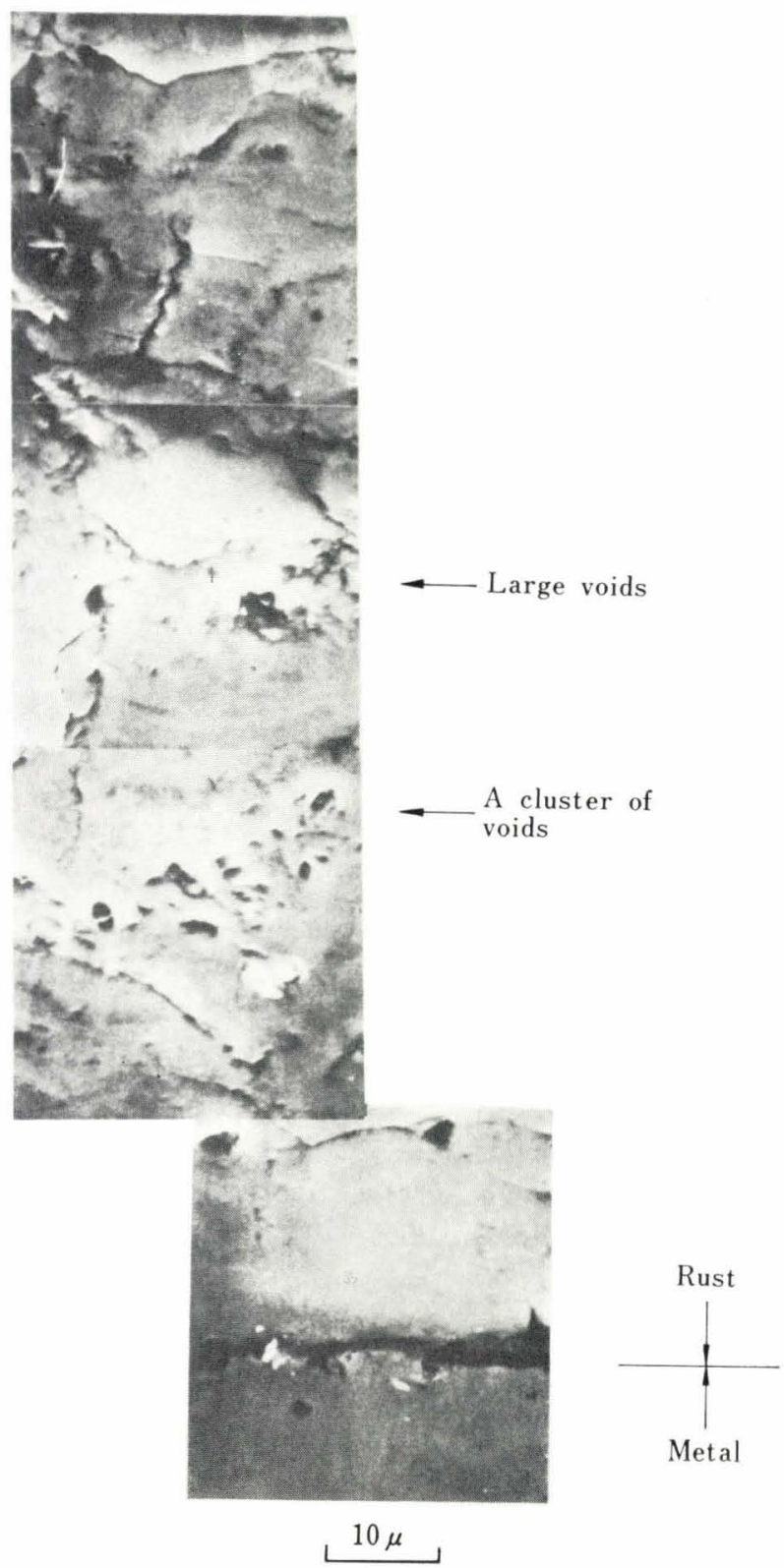

Photo. 4. Scanning electron micrograph of the rust in a large pit showing various defects such as voids and cracks. The same area as in Photo. 3 left. 
rounding pits exhibits a different pattern of distribution as shown in Photo. 6.

Sulfur: more sulfur is contained than in steel. It is concentrated at the rust-air interface.

Copper: no concentration of copper is observed.

Chromium: the fact that chromium is hardly found characterizes the rust on the surface surrounding pits.

Phosphorus: no local concentration of phosphorus is observed.

Nickel: no local concentration of nickel is observed.

Manganese: no local concentration of manganese is observed.

Silicon: silicon is dotted in the rust and is especially concentrated near the rust-air interface. The layer without silicon is found at the rust-metal interface. As oxygen coexists in the portion of high silicon content, the inclusion seems to be accumulated dust particles embedded in rust layer.

As to the carbon steel, it was also confirmed that silicon was contained only in the surface layer of the rust within pits as well as within rust layer on the steel surface out of pits while a thick layer where no silicon was detected existed at the rust-metal interface.

The pits formed on the steel exposed at Nagano for three years were smaller than those exposed at Amagasaki and the rust layer of Nagano specimens was thinner than that of Amagasaki specimens as shown in Photo. 7. The distribution of the alloying elements of the rust at Nagano indicated in Photos. 8 and 9, however, was just the same as that at Amagasaki. Chromium, phosphorus, and copper were concentrated in the rust within pits but hardly found in the rust overlying the pits. Such concentration of chromium and sulfur as was seen in the large pits was found in small pits formed on the comparatively even steel surface surrounding the large pits.

The distribution of the alloying elements in the rust formed on the low alloy steel $B$ exposed at Amagasaki for seven years is shown in Photo. 10.

Sulfur: although the surface layer is relatively high in sulfur content, sulfur is distributed over the whole rust and particularly notable local concentration is not observable.

Copper: no local concentration of copper is observed.

Chromium: stratified local concentration of chromium is found within the pits and no chromium is present in the rust overlying the pits. The rust on the flat surface surrounding the pits does not contain chromium.

Phosphorus: local concentration of phosphorus is appreciable in the pits.

Nickel: no local concentration of nickel is observed.

Silicon: only surface layer of rust contains silicon.

The results from the observations mentioned above indicate that the local concentrations of chromium, phosphorus, and copper are limited in the rust within pits and that the rust on the flat surface surrounding the pits and the rust overlying the pits contain a small quantity of chromium, phosphorus, and copper, each local concentration of which is hardly observable. Figure 3 indicates relative intensity profiles of alloying elements in the rust, microstructure of which is shown in Photo. 2 (b). Local concentration of the elements in the rust layer overlying the pit seems to be exceptional. As the rust layer out of pits contains silicon, it seems to be
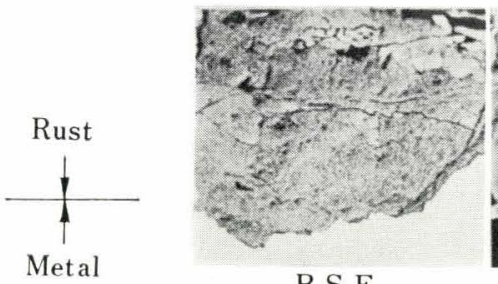

B.S.E.

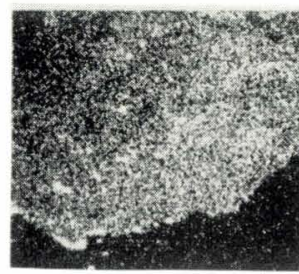

S

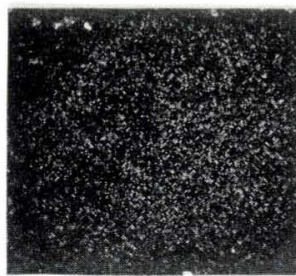

$\mathrm{Si}$

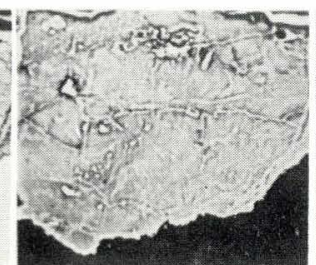

S.C.

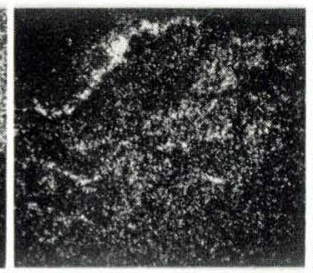

$\mathrm{Cr}$

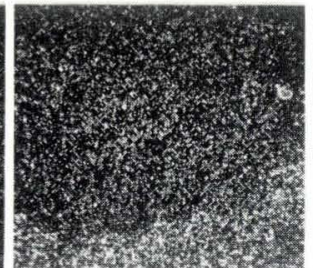

$\mathrm{Mn}$

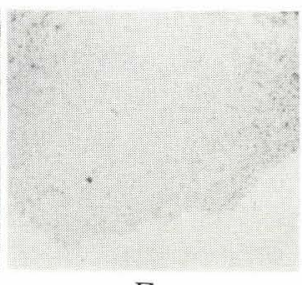

$\mathrm{Fe}$

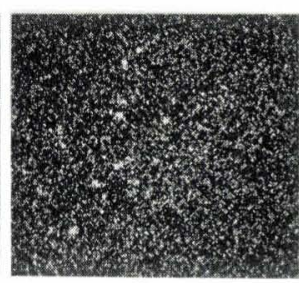

$\mathrm{Cu}$

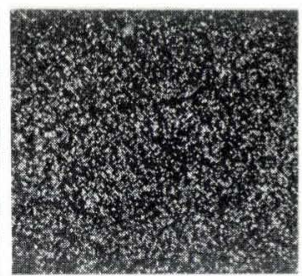

$\mathrm{Ni}$

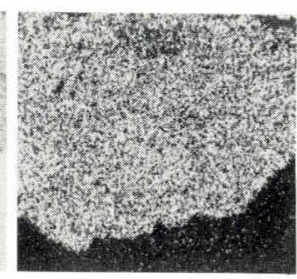

O

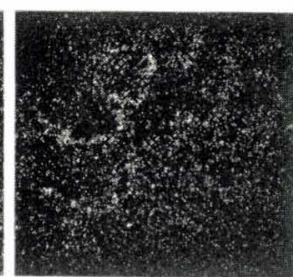

$\mathrm{P}$

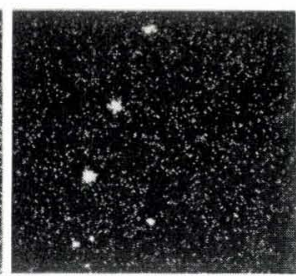

$\mathrm{Ti}$

Photo. 5. EBS images of EPMA of the rust in a large pit formed on low alloy steel $A$ by three years' atmospheric exposure in industrial area (See Photo. 3 left) (S.C.: specimen current image) 


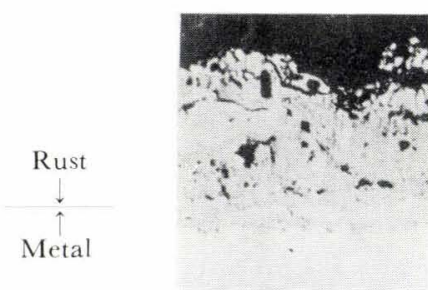

B.S.E

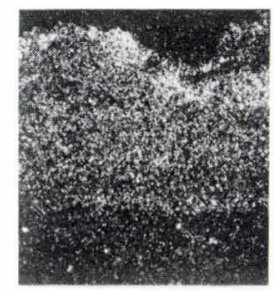

S

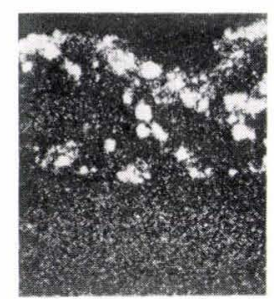

Si

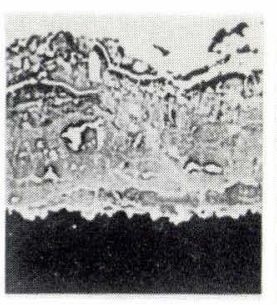

S.C.

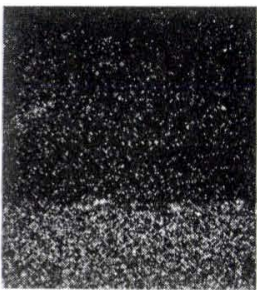

$\mathrm{Cr}$

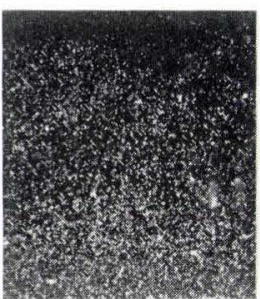

$\mathrm{Mn}$

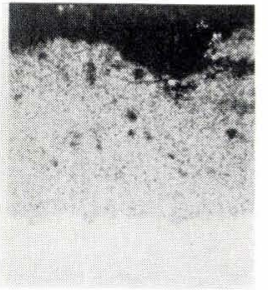

$\mathrm{Fe}$

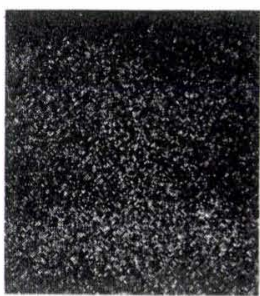

$\mathrm{Cu}$

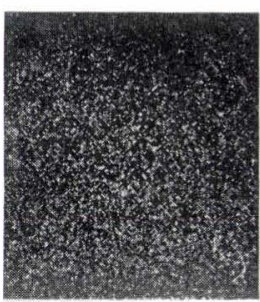

$\mathrm{Ni}$

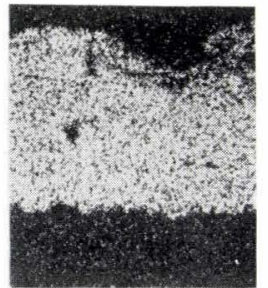

$\mathrm{O}$

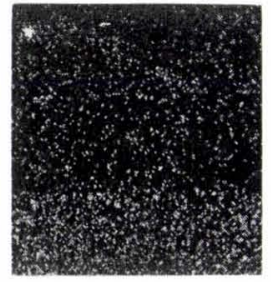

$\mathrm{P}$

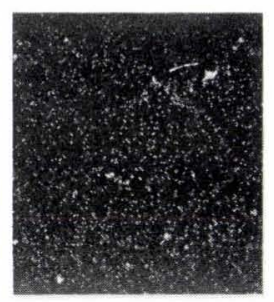

$\mathrm{Ti}$

$50 \mu$

Photo. 6. EBS images of EPMA of the rust on a part of less pitted surface of low alloy steel $A$ formed by three years' atmospheric exposure in industrial area (See Photo. 3 right)

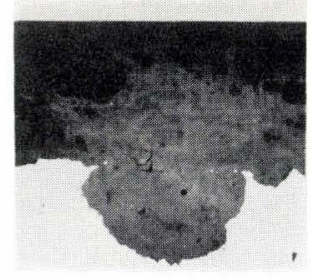

$50 \mu$

(a)

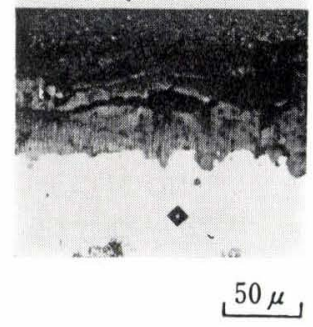

(b)

Photo. 7.

Microstructure of the rust layers formed on low alloy steel $A$ by three years' atmospheric exposure in rural area

(a) Rust in a pit

(b) Rust on less pitted surface

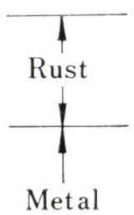

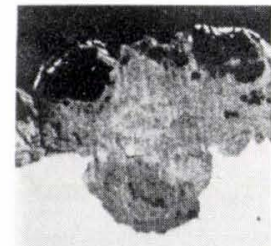

B.S.E.

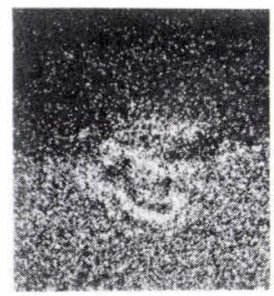

$\mathrm{Cr}$

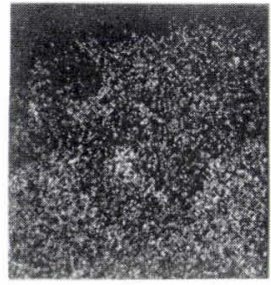

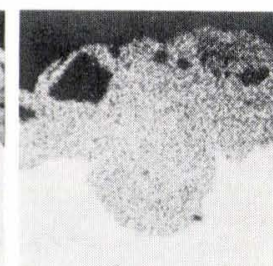

$\mathrm{Fe}$

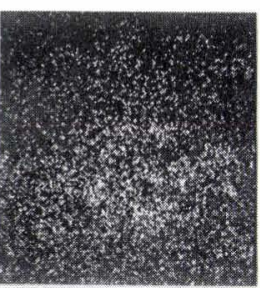

$\mathrm{Cu}$

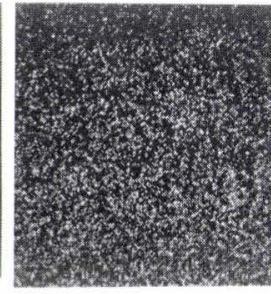

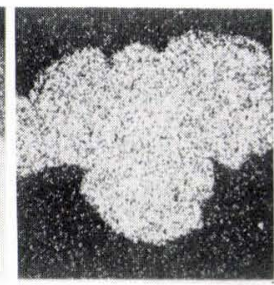

O

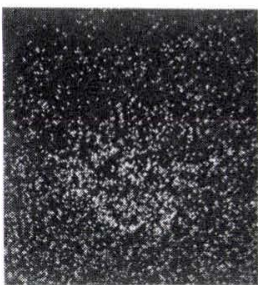

$\mathrm{P}$

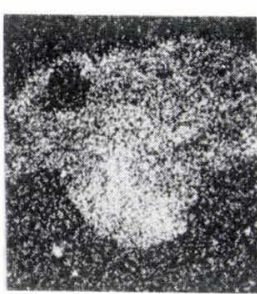

$\mathrm{S}$

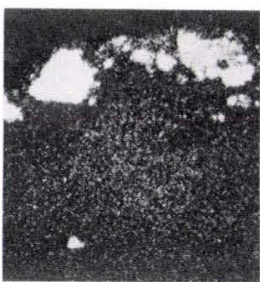

Si
$\mathrm{Mn}$

$\mathrm{Ni}$

$50 \mu$

formed by the precipitation of iron ion which diffuses out from the pits enveloping dust particles. The change in weight of the adherent rust with time shows that the rust initially deposited rapidly on the specimen

\section{Photo. 8.}

EBS images of EPMA of the rust in a pit of low alloy steel $A$ formed by three years' atmospheric exposure in rural area (See Photo. 7 (a))

surface and after certain period the iron ion produced by further corrosion ran out from the specimen without accumulation and the quantity of the ions which precipitate in the pits would be small. Oxides or 


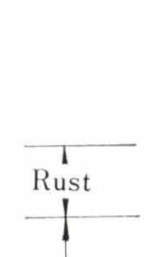

Metal
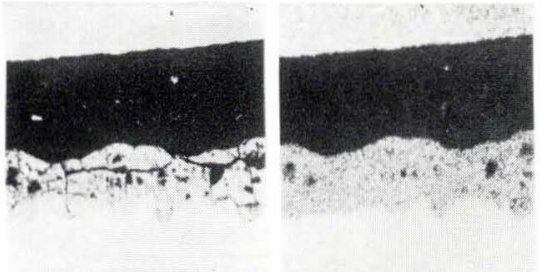

$\mathrm{Fe}$

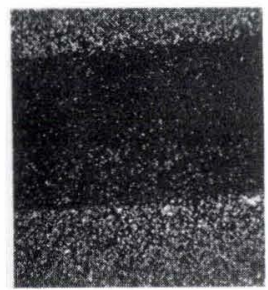

$\mathrm{Cr}$

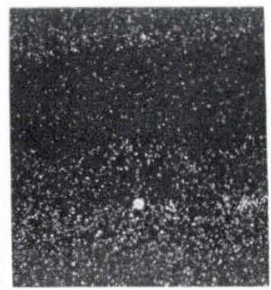

$\mathrm{P}$

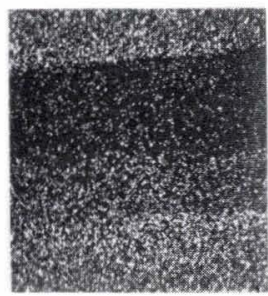

$\mathrm{Ni}$

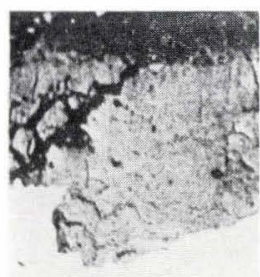

B.S.E.

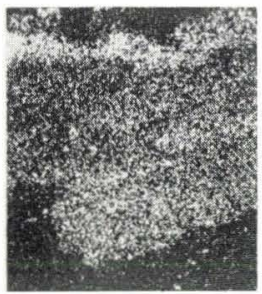

$\mathrm{S}$

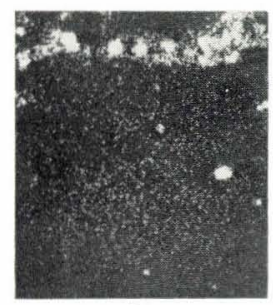

$\mathrm{Si}$

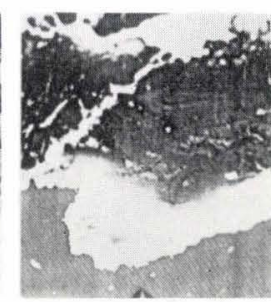

S.C.

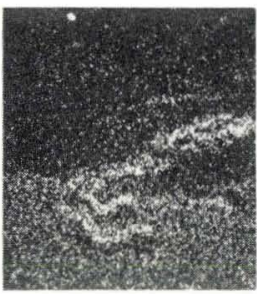

$\mathrm{Cr}$

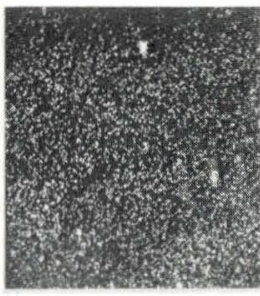

$\mathrm{Mn}$

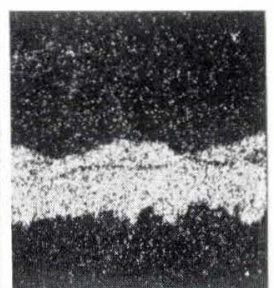

$\mathrm{O}$

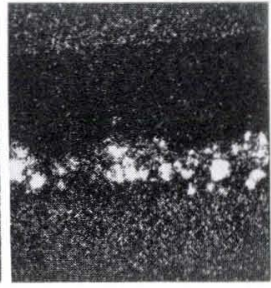

Si

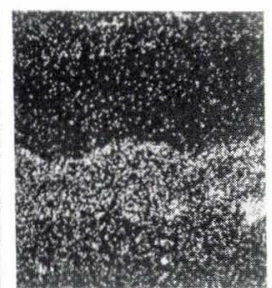

$\mathrm{S}$

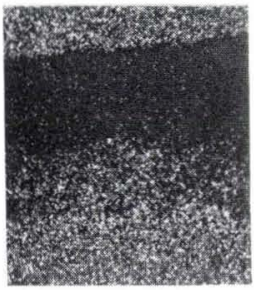

$\mathrm{Mn}$

Photo. 9

EBS images of EPMA of the rust on less pitted surface of low alloy steel $A$ formed by three years' atmospheric exposure in rural area (See Photo. 7 (b))

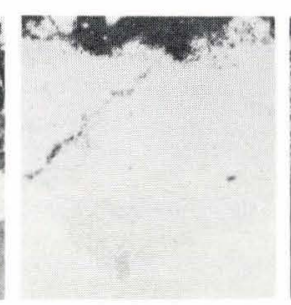

$\mathrm{Fe}$

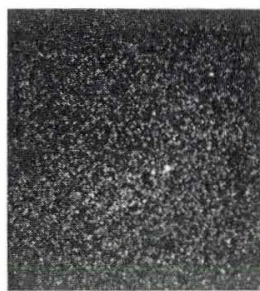

$\mathrm{Cu}$

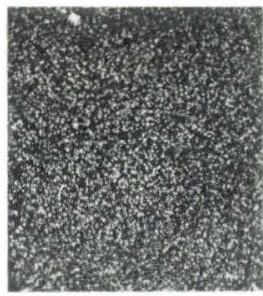

$\mathrm{Ni}$

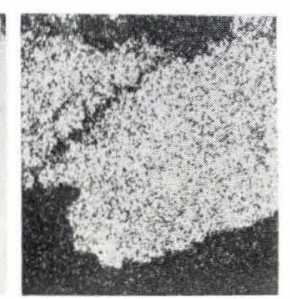

$\mathrm{O}$

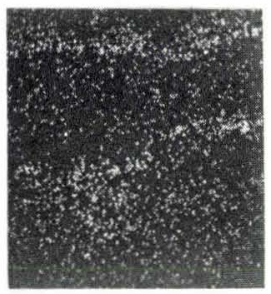

$\mathrm{P}$
Photo. 10.

EBS images of EPMA of the rust formed on low alloy steel $B$ by seven years' atmospheric exposure in industrial area hydroxides of chromium and copper which are less soluble than those of iron, however, possibly precipitate in and around the microcracks and the voids of the rust in the pits. The solubility products of $\mathrm{Cu}(\mathrm{OH})_{2}$, $\mathrm{Cr}(\mathrm{OH})_{2}, \mathrm{CrPO}_{4}$ and $\mathrm{FePO}_{4}$ are less than one-thousandth of that of $\mathrm{Fe}(\mathrm{OH})_{2}$. Since their precipitation occurs in the microcracks, the voids and the rust around them which contain water, the precipitates would gradually plug up those defects. The reason why decrease in corrosion rate of the carbon steel with time is smaller than that of the low alloy steels seems to be attributed to lack of the plugging action by the alloying elements.

\section{Conclusions}

Conclusions are drawn as follows as a result from 


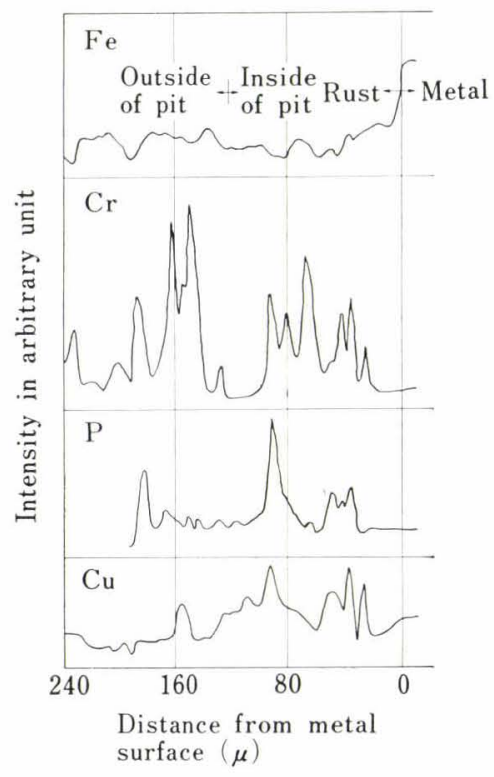

Fig. 3. Distribution of alloying elements in the rust layer of low alloy steel $A$

the investigation on the distribution of the alloying elements in the rust layer which improve the corrosion resistance of atmospheric corrosion resistant steel.

(1) Pits are formed on the steel surface by atmospheric corrosion. The pits of atmospheric corrosion resistant steel do not grow large and are surrounded by the surface on which small pits exist but most of the surface remains smooth. The distribution of the alloying elements in the rust layer within the pits and that on the surrounding surface are quite different.

(2) Local concentration of chromium, phosphorus, and copper in rust within the pits is observed. The coincidence of concentrated chromium and phosphorus around the defects is found. Local concentrations of copper and sulfur which are located in the portions close each other become less intense after a long period of atmospheric exposure.

(3) No local concentration of the alloying elements is found in the rust on the pits and on the flat surface surrounding pits. It is revealed that chromium is not contained by the rust out of the pits. Local concentration phenomenon seems to be confined to the rust within pits.

(4) Distribution of dust particles indicates that the rust overlying the pits and on the flat surface surrounding the pits is formed by precipitation of iron ions which are originated and diffuse out from the pits enveloping the dust particles.

(5) Local concentration of the alloying elements in the rust within the pits is formed by the diffusing out of iron ion from pits and simultaneous precipitation of chromium, phosphorus, and copper compounds in the pits which have less solubility product than that of $\mathrm{Fe}(\mathrm{OH})_{2}$. The fact that as the precipitation in the defects like cracks and voids in the pits proceeds, the defects would be plugged up, would be a cause of the development of the protectiveness of the rust layer of atmospheric corrosion resistant steel.

\section{REFERENCES}

1) J.B. Horton: Pittsburgh Regional Tech. Meeting AISI, Nov., (1965).

2) I. Matsushima and T. Ueno: Tetsu-to-Hagané, 54 (1968), S257.

3) Preprints (Abstract) for the 63rd Conference of The Japan Institute of Metals, (1968), 290.

4) H. Okada, Y. Hosoi, K. Yukawa, and H. Naito: Tetsu-toHagané, 55 (1969), 355.

5) N. Masuko and Y. Hisamatsu: Corrosion Engineering, 17 (1968), 539.

6) Preprints (Abstract) for the 65th Conference of The Japan Institute of Metals, (1969), 121. 